THE Journal OF THE Brazilian Crustacean Society

e-ISSN 2358-2936 www.scielo.br/nau www.crustacea.org.br

\title{
Swimming behavior of newly hatched larvae of six decapod species (Crustacea: Decapoda)
}

\author{
Eduardo Vianna de Almeida ${ }^{1}$ (D) orcid.org/0000-0001-8219-0968
}

Carolina dos Santos Cardoso² (D) orcid.org/0000-0002-9473-6144

Manoela dos Santos Souza ${ }^{3}$ (D) orcid.org/0000-0003-2504-2875

Sérgio Luiz Costa Bonecker ${ }^{4}$ (D) orcid.org/0000-0001-8156-6900

1 Laboratório de Carcinologia (A1-97), Instituto de Biologia da Universidade Federal do Rio de Janeiro (UFRJ). Av. Carlos Chagas Filho, n. 373, Centro de Ciências da Saúde (CCS) - Cidade Universitária, 21941-902 Rio de Janeiro, Rio de Janeiro, Brazil. EVA E-mail: vianna.almeida@gmail.com

2 Pós Graduação em Meio Ambiente, Universidade do Estado do Rio de Janeiro (UERJ). Instituto de Biologia Roberto Alcantara Gomes, Pavilhão Américo Piquet Carneiro (PAPC). Rua Boulevard 28 de Setembro, 87, 20551-030 Rio de Janeiro, Rio de Janeiro, Brazil.

sCs E-mail: biocarolina@gmail.com

3 Faculdades Integradas Maria Thereza (Famath). Av. Visconde do Rio Branco, 869, 24210-006 Niterói, Rio de Janeiro, Brazil.

MSS E-mail: manoelasandre@gmail.com

4 Laboratório Integrado de Zooplâncton e Ictioplâncton (A0-84), Instituto de Biologia da Universidade Federal do Rio de Janeiro (UFRJ). Av. Carlos Chagas Filho, 373, 21941-902 Rio de Janeiro, Rio de Janeiro, Brazil.

SLCB E-mail: bonecker@biologia.ufrj.br

ZOOBANK: http://zoobank.org/urn:lsid:zoobank.org:pub:2F9A54C7-FA26-4A118A66-9C5DDDF8EB63

\section{Abstract}

Crustacean decapod larvae have developed several adaptations to maximize their survival, including swimming behavior. Swimming improves larvae dispersal and contributes to their response to environmental stresses, including variations in abiotic factors, presence of predators, and search for food. Data on larval behavior can also assist in studies on conservation and in species management in aquaculture. Unfortunately, swimming behavior remains unstudied in many species. The present work aims to analyze the swimming behavior in newly hatched larvae of six common decapod crustaceans in coastal Southeast Brazil (Macrobrachium acanthurus, Macrobrachium olfersii, Emerita brasiliensis, Ucides cordatus, Minuca rapax, and Callinectes danae). The analysis included tests with larval responses to four isolated stimuli: gravity (geotaxis), vertical salinity gradients, low-pressure zones, and presence of the planktivorous fish, Atherinella brasiliensis (only for $C$. danae and M. rapax). The first two and the last two stimuli were used as indicators of dispersal and defensive behaviors, respectively. All larvae 
preferred water depth with higher salinity levels. Additionally, negative geotaxis was observed in M. olfersii, M. acanthurus, U. cordatus, and C. danae, being stronger in the last. Both Macrobrachium larvae responded to low-pressure zones, promptly moving away. Callinectes danae and M. rapax larvae avoided contact with the predatory fish by creating avoidance zones around it, even in the absence of light. This is an active defensive behavior that has never been reported for the newly hatched larvae of these two species.

\section{KeYWORDS}

Callinectes danae, Emerita brasiliensis, Macrobrachium, Minuca rapax, Ucides cordatus

\section{INTRODUCTION}

Zooplankton swimming behavior, especially the regulation of vertical positioning, can maximize, minimize, and guide the organism's transport (Seuront et al., 2004). In addition, swimming behavior permits avoiding passive sinking, predation, and unfavorable environmental conditions (Saiz, 2009). Decapod larvae (Crustacea, Malacostraca) are important members of the zooplankton community, but have received little attention regarding their swimming behavior. Despite advances in recent decades, many of the studies on decapod larvae are still restricted to descriptions of external morphology and the number of pelagic stages, since there are many undescribed larvae (Koettker and Freire, 2006). Even considering the ecological and economic importance of decapods, larval behavior in many species remains unknown. The study of swimming behavior allows the recording of valuable data, such as response to environmental factors, dispersal strategies, and population dynamics (Epifanio and Cohen, 2016). These studies can also provide important information to help species conservation, monitoring, and management in aquaculture systems.

Larval swimming behavior and the position in the water column are important factors in the dispersal and defense of many species (Anger, 2001). The direction and velocity of currents vary within the water column, and larval position can determine their transport potential (Kunze et al., 2013). Several decapods have larval export mechanisms, which move the larvae away from the spawning site and improve their dispersal. The newly hatched larvae from species with export mechanisms usually present negative geotaxis, swimming in subsurface waters during ebb tides to achieve more effective transport and dispersal (Anger, 2001). The goal of larval export is also to reach coastal waters with higher salinities for the riverine prawns Macrobrachium acanthurus (Wiegmann, 1836) and Macrobrachium olfersii (Wiegmann, 1836) (Caridea: Palaemonidae), and estuarine species such as the mangrove crab Ucides cordatus (Linnaeus, 1763) and the fiddler crab Minuca rapax (Smith, 1870) (Brachyura: Ocypodidae). The larvae of these decapods, as observed in many other species, need salinities above 15-20 PSU to successfully develop (Choudhury, 1971; McNamara et al., 1986; Diele and Simith, 2006; Simith et al., 2014). Another goal of dispersal is to quickly leave the spawning sites, where predation pressure may be higher, as observed in most estuaries and other coastal environments (Morgan and Christy, 1997).

In portunid crabs, such as the blue crab Callinectes danae Smith, 1869 (Brachyura: Portunidae), commonly found in estuaries, including bays, coastal lagoons, and habitats near mangroves, larvae can be transported several kilometers between where they are released and where they settled (Forward et al., 2003). Similarly, the mole crab Emerita brasiliensis Schmitt, 1935 (Anomura: Hippidae), which is common in sandy intertidal zones (Veloso et al., 2006), present a larval phase that lasts $2-3$ months and has high dispersal potential (Otegui and Soares-Gomes, 2007).

Considering the lack of information on the larval swimming behavior of the species mentioned above, the present study analyzes it in newly hatched larvae of six decapod crustaceans: M. acanthurus, M. olfersii, E. brasiliensis, U. cordatus, $M$. rapax, and C. danae. Larval swimming responses to isolated stimuli of 
gravity (geotaxis), vertical salinity gradients, lowpressure zones, and the presence of the planktivorous fish Atherinella brasiliensis (Quoy and Gaimard, 1825) (in C. danae and $M$. rapax only) were tested. The first two stimuli are related to dispersal behavior and the last two to defensive behavior. The species cited above are common on the southeastern coast of Brazil, being abundant in their respective ecosystems. Macrobrachium olfersii, $M$. acanthurus, C. danae, and especially $U$. cordatus, are heavily exploited in the region. These species, as well as E. brasiliensis and $M$. rapax, have an important role in the transfer and/ or recycling of organic matter in their ecosystems.

\section{Material and Methods}

Female sampling and larval rearing

Ovigerous females with eggs in the final stage of development were manually collected by the use of fishing nets. All sampling areas were located in Rio de Janeiro State, southeastern Brazil (Fig. 1). Female sampling occurred during the New or Full Moon phases, due to their synchronized spawning (Anger, 2001). Macrobrachium females were collected in the
Sahy River (municipality of Mangaratiba), between March and July 2005. The females of M. acanthurus were obtained in the estuarine region and downstream (between 22 $56^{\prime} 17^{\prime \prime} \mathrm{S} 044^{\circ} 00^{\prime} 14^{\prime \prime} \mathrm{W}$ and $22^{\circ} 55^{\prime} 56^{\prime \prime} \mathrm{S}$ $044^{\circ} 00^{\prime} 17^{\prime \prime}$ W). Macrobrachium olfersii females were obtained upstream, following the course of the river and natural pools (between $22^{\circ} 55^{\prime} 11^{\prime \prime} \mathrm{S} 043^{\circ} 59^{\prime} 44^{\prime \prime}$ W and 22 $54^{\prime} 56^{\prime \prime} \mathrm{S} 043^{\circ} 59^{\prime} 37^{\prime \prime} \mathrm{W}$ ).

Blue crab females (C. danae) were obtained in Itaipu Lagoon (22 57’35” S $\left.043^{\circ} 02^{\prime} 31^{\prime \prime} \mathrm{W}\right)$, in the municipality of Niterói. Minuca rapax females were obtained in the same lagoon, at the Camboatá Mangrove channel. Females of both species were caught on two occasions: between June and September 2007 and in April 2012. This last campaign aimed to obtain larvae for the contact tests with planktivorous fish.

Females of the sand crab (mole crab) E. brasiliensis were collected on the west side of Itaipuaçu Beach, municipality of Maricá (22 $58^{\prime} 11^{\prime \prime} \mathrm{S} 043^{\circ} 00^{\prime} 24^{\prime \prime}$ W), between August and September 2008. Finally, the U. cordatus females were obtained in Porto do Rosa Mangrove, municipality of São Gonçalo (inner Guanabara Bay, 2247'13” S 04303’26” W) in February 2012.

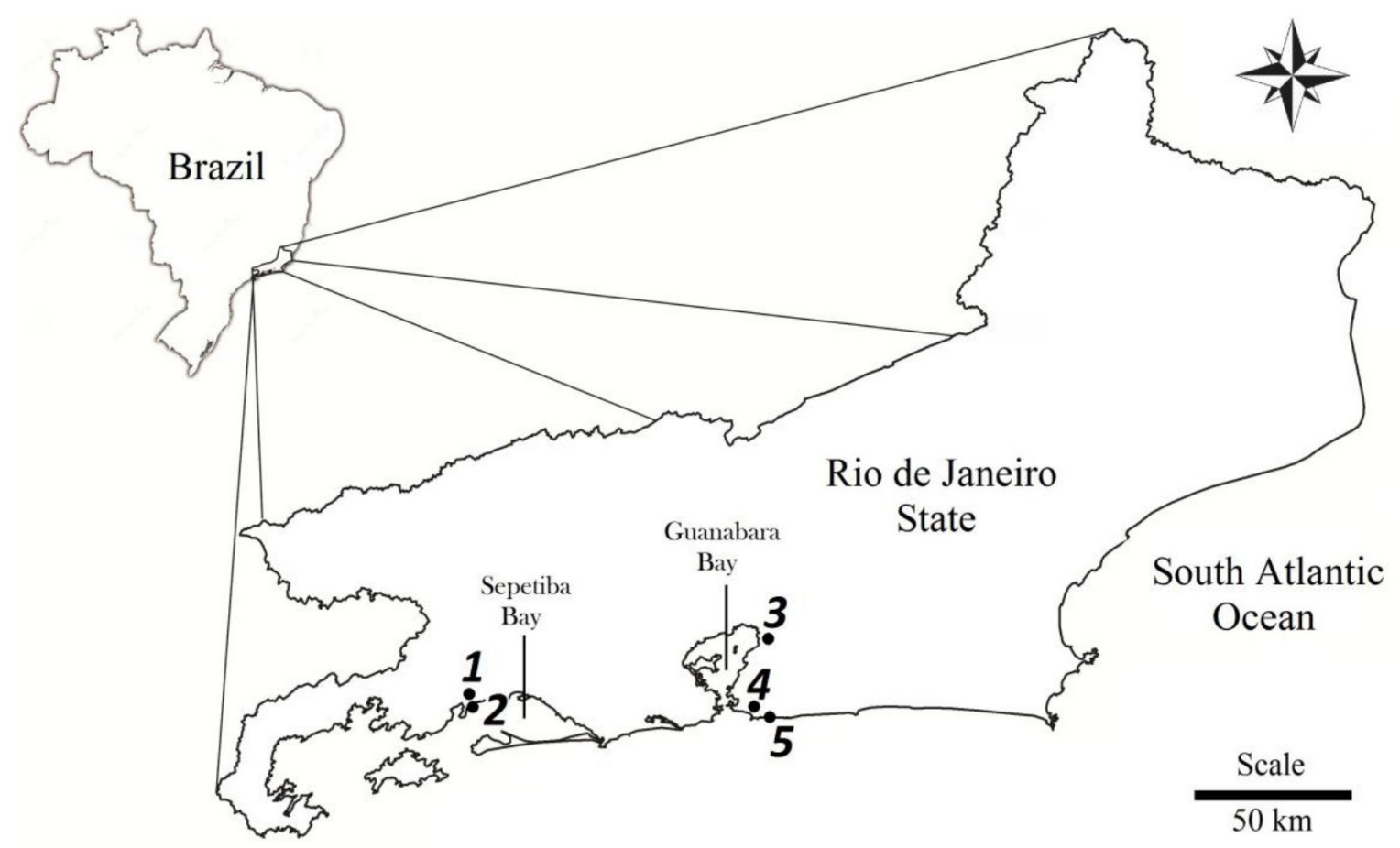

Figure 1. Location of the sampling areas in SE Brazil: 1) Macrobrachium olfersii, Sahy River upstream, 2) Macrobrachium acanthurus, Sahy River estuary, 3) Ucides cordatus, Porto do Rosa Mangrove, 4) Minuca rapax and Callinectes danae, Itaipu Lagoon, 5) Emerita brasiliensis, Itaipuaçu Beach. 
All specimens were transported to the laboratory and individually placed in aerated spawning tanks of 5.0-10.0 liters, under $12 \mathrm{~h}: 12 \mathrm{~h}$ reverse photoperiod (i.e., dark period from $6.00 \mathrm{~h}$ to $18.00 \mathrm{~h}$ ) and temperature was kept at $25 \pm 1{ }^{\circ} \mathrm{C}$. Water from the sampling areas or adjacent coasts was used. Salinity was 15.0 PSU in the Macrobrachium spawning tanks and 30.0 PSU in the other tanks. During the experiments, salinity was measured with a manual refractometer, which was previously calibrated and kept clean with the aid of distilled water. In the U. cordatus and M. rapax spawning tanks, sterile PVC pipes were placed as shelters. The bottom of the E. brasiliensis tanks were covered with washed sand from the sampling site. Also, cones with a mesh width of $200 \mu \mathrm{m}$ were placed $10.0 \mathrm{~cm}$ above the bottom to avoid contact between newly hatched larvae and the planktivorous adults. All females were kept in starvation until spawning. Immediately after the larval release, the females were removed and the more active larvae were transferred to gently aerated 2.0 liter beakers, with the aid of a pipette.

In the Macrobrachium tanks, a cover net was necessary because some females jumped out of the aquaria. The $U$. cordatus females showed more sensitivity during collection and transportation to the laboratory. Due to their stress, it was necessary to catch 12 females to obtain five successful spawns.

\section{Experiments}

Only the actively swimming newly hatched larvae were used in the swimming behavior tests (zoea I, in its first 12h). The larvae were not fed and all the experiments were performed in triplicate, with mixed larvae from five females of each species ( 40 per female). In all tests, observations of the larval behavior were made at the same time by three watchers, once every 15 minutes. To observe the aquariums in the absence of light, a small LED flashlight (white light, 65 lumens) was used, and the observation was quickly performed (maximum 30 seconds) to avoid disturbance of the experiment. Counting of the larvae was with the use of hand counters. Except for the planktivorous fish tests, the experiments lasted for one hour.

\section{Geotaxis test}

To test the swimming response to gravity, 200 larvae of each species were placed in a transparent glass tank in the shape of a column (H120, W12, D8 $\mathrm{cm})$. One hundred larvae were placed at the bottom of the column and another 100 next to the surface. The salinity was the same as in the spawning tanks and the column was kept in the dark. The column tank was marked every $5.0 \mathrm{~cm}$ to facilitate the observation of larval position. Negative geotaxis was considered when most of the larvae swam and remained in the upper half of the column. When the opposite occurred, it was considered positive geotaxis. The absence of geotaxis was considered when the larvae were distributed evenly along the entire column, with no apparent pattern. To verify whether the number of larvae in the upper half of the tank was significantly different from that observed in the lower half, the normality (Shapiro-Wilk test) and homogeneity (Levene's test) of the data was checked. After verifying these assumptions, a Student T-Test was performed considering the significance level of $p<0.005$. These analyzes were conducted using JAMOVI software (2020).

\section{Salinity gradient test}

The vertical salinity gradient test was made in the same columnar tank used in the geotaxis tests. In this test, the tank was filled with water, at a salinity of 30 PSU in the lower half and 15 PSU in the upper. The addition of the upper half water was made carefully so that the halocline did not surpass the $10 \mathrm{~cm}$ mark. The column was kept at $25^{\circ} \mathrm{C}$ and protected from light. Previously acclimated larvae (to each salinity) were placed simultaneously in the lower and upper halves, respectively (100 each). At the end of the test, salinity was verified in the entire column to access possible changes in the halocline position or range. At the end of the test, salinity was checked again at the depths with high larval concentration. To verify if the number of larvae in the range with the highest salinity was significantly different from that observed in the range with lower salinity, the same methodology described in the geotaxis test was used. 


\section{Low-pressure zone test}

Before the first experiments performed with the Macrobrachium species, we observed a larval escape reaction, whenever they were captured with a pipette. These reactions occurred when the pipette tip approached them during the suction of water. This has been interpreted as a response to low-pressure zones and is probably a defensive reaction. Many predators, like fishes and filter feeders, create low-pressure zones when aspirating their prey. Thus, the larval swimming behavior, when they approached a low-pressure zone, was evaluated (under a stereomicroscopic microscope, 40x). The low-pressure zone was created by aspirating water close to the larvae, using a glass pipette $(15 \mathrm{ml})$ with a rubber bulb. The larval reaction was analyzed in 100 larvae of each species.

\section{Planktivorous fish test}

The planktivorous fish, Atherinella brasiliensis, also known as the "silverside", was captured in the Itaipu Lagoon. The fish specimens were taken to the laboratory and kept in previously acclimated aquaria, with proper aeration, water circulation and the temperature kept at $25^{\circ} \mathrm{C}$. The tests were performed within 48 hours after the fish were caught, and they were not fed.

Five-liter tanks with one fish per liter and high larval densities (from 800 to 2200 larvae. $^{1-1}$ ) were set up (Tab. 1). There were eight aquaria with larvae of $M$. rapax and four with larvae of $C$. danae. Half

Table 1.Luminosity and larval density (larvae. $\mathrm{l}^{-1}$ ) in experimental tanks with Callinectes danae and Minuca rapax newly hatched larvae in the presence of the planktivorous fish Atherinella brasiliensis. $(\circ)=$ light tanks; $(\bullet)=$ dark tanks.

\begin{tabular}{ccc}
\hline Species & Luminosity & ${\text { Larvae. } \mathbf{I}^{\mathbf{1}}}^{\text {Callinectes danae }}$ \\
\hline & $\circ$ & 800 \\
Minuca rapax & $\bullet$ & 1100 \\
& $\bullet$ & 2200 \\
& $\circ$ & 1600 \\
& $\circ$ & 2010 \\
& $\circ$ & 1190 \\
& $\circ$ & 2200 \\
& $\bullet$ & 1170 \\
& $\bullet$ & 1230 \\
& $\bullet$ & 1750 \\
& $\bullet$ & 1050 \\
\hline
\end{tabular}

of the aquaria remained in the dark during the test. The others were illuminated by artificial white light from the ceiling (60-Watt fluorescent lamp, $\approx 550$ lumens). Larvae and fish remained in the same tanks for 30 minutes. Immediately after removal, the fish were frozen at $-18.0^{\circ} \mathrm{C}$. Then, the larval density in the aquaria was evaluated (by subsampling) and the fish were dissected to evaluate their stomach contents and the presence of crab larvae, following Amundsen et al. (1996).

\section{Results}

Spawning always occurred at the beginning of the dark period (in the reverse photoperiod) and during the first $48 \mathrm{~h}$ with the presence of females in the aquaria. During the performance of the experiments, larvae of all species showed positive phototaxis, swimming towards the light sources, or concentrating in the most illuminated points in the aquarium. However, phototaxis experiments were not carried out with the methodology recommended by other authors (see discussion).

\section{Geotaxis test}

Macrobrachium olfersii $(67 \pm 2.1 \%)$, M. acanthurus (78 $\pm 1.9 \%)$, C. danae (91 $\pm 1.3 \%)$, and U. cordatus (75 $\pm 2.9 \%)$ larvae showed negative geotaxis, swimming in the subsurface layer (above $15 \mathrm{~cm}$ depth) (Fig. 2). For these species, the number of larvae in the upper half of the column was significantly higher than in the lower half $(p<0.001)$. The larvae introduced in the lower part of the aquarium moved to the upper part of the column, within 15 minutes, and remain there until the experiment ended. Emerita brasiliensis and M. rapax larvae did not respond to gravity, swimming throughout all the water column. This pattern was also established in the first 15 minutes and remained until the end of the experiment.

\section{Salinity gradients test}

In vertical salinity gradients, $93 \pm 2.2 \%$ of $M$. olfersii larvae swam in the halocline depth, where salinity varied from 16.0 to 20.0 PSU. Most M. acanthurus larvae remained in depths with salinity levels between 18.0 and 30.0 PSU (63 $\pm 1.7 \%)$. Most 
C. danae $(74 \pm 3.0 \%)$, U. cordatus $(85 \pm 5.0 \%)$, and $M$. rapax $(84 \pm 1.4 \%)$ larvae swam in depths with higher salinity (30 PSU) (Fig. 3). Most E. brasiliensis larvae $(80 \pm 2.7 \%)$ swam in waters with high salinity and the rest in the halocline region. These patterns of larval distribution were established about 15 to 30 minutes after the experiment's beginning and remained the same until the end. In all species, the distribution of larvae above and below halocline was significantly different $(p<0.001)$.

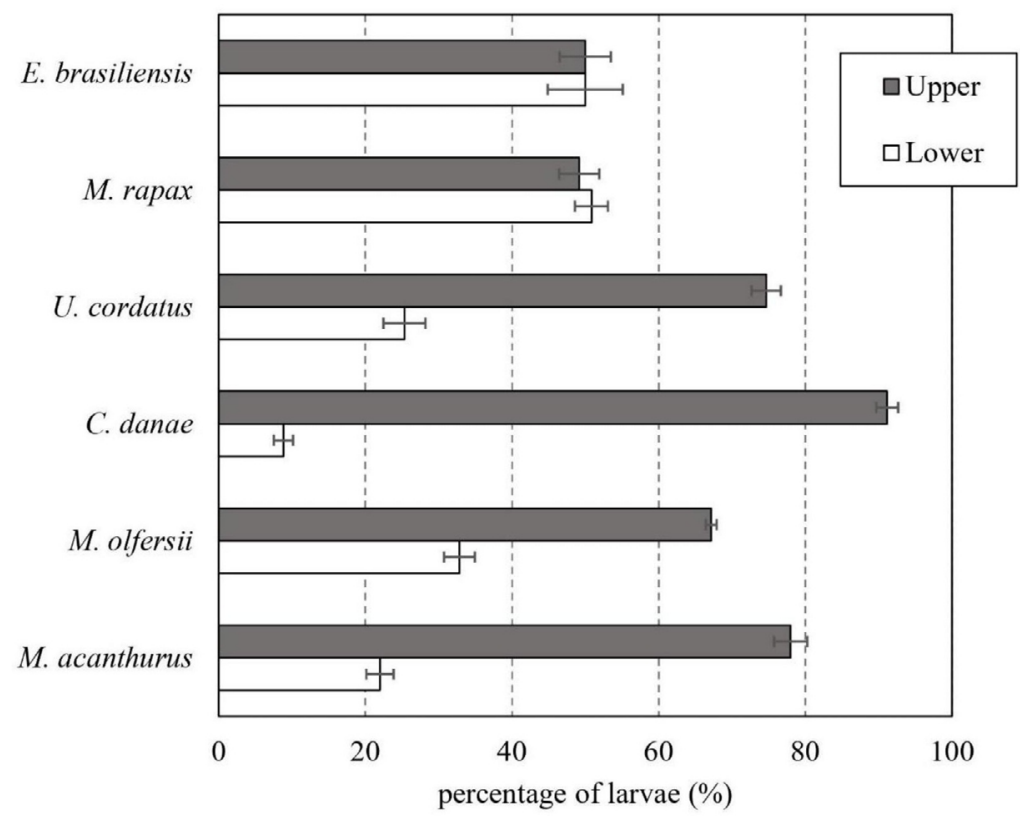

Figure 2. The response of zoea I to gravity (Emerita brasiliensis, Minuca rapax, Ucides cordatus, Callinectes danae, Macrobrachium olfersii, and Macrobrachium acanthurus). Bars represent the mean percentage of larvae \pm standard deviation in upper and lower halves of a columnar tank, established after the first 15 minutes until the end of the experiment (total duration: 1 hour).

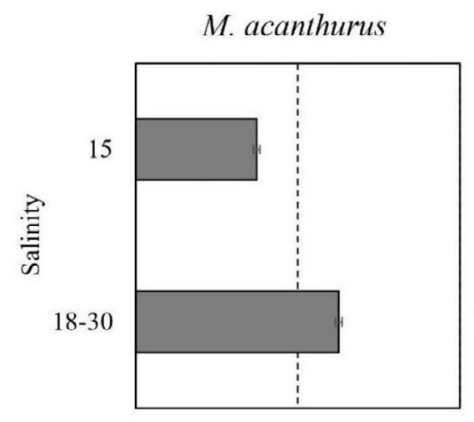

U. cordatus

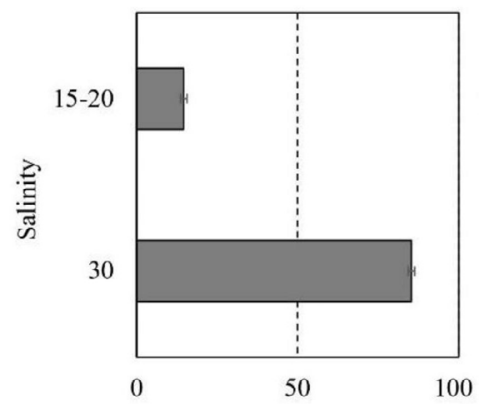

M. olfersii

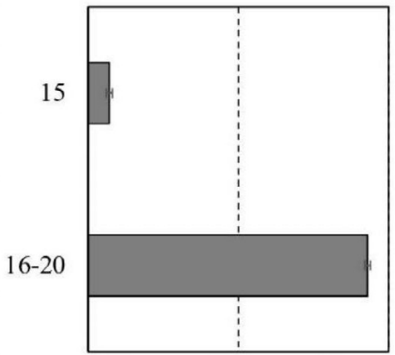

M. rapax

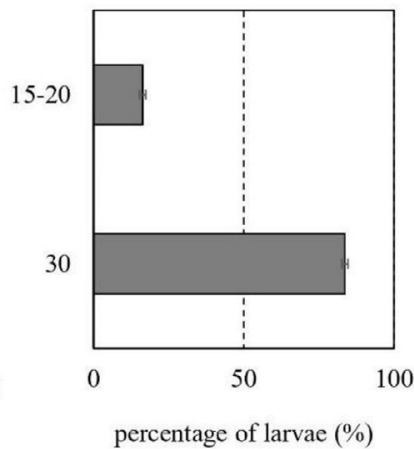

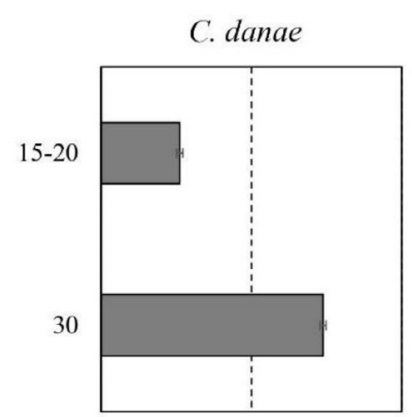

E. brasiliensis

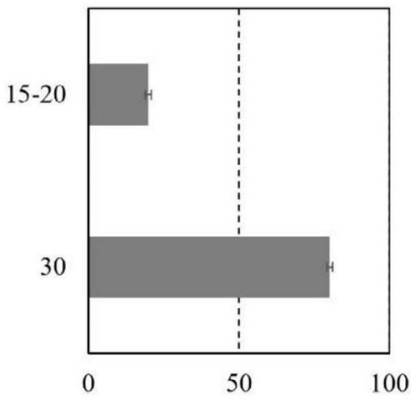

Figure 3. The response of zoea I to the presence of a halocline (Emerita brasiliensis, Minuca rapax, Ucides cordatus, Callinectes danae, Macrobrachium olfersii, and Macrobrachium acanthurus). Bars represent the mean percentage of larvae \pm standard deviation in a salinity (or salinity range), established after the first 15-30 minutes until the end of the experiment (total duration: 1 hour). 


\section{Low-pressure zone test}

In the low-pressure zone tests, only the two Macrobrachium species responded to the stimulus. Their larvae quickly reacted to the oncoming of lowpressure zones, executing strong swimming pulses that took them 10 to $15 \mathrm{~cm}$ away. The larvae of the other species did not react to low-pressure zones, even when they were close together. These larvae were pumped by the pipette and no escape reaction was observed.

\section{Planktivorous fish test}

In the experiments, with $C$. danae and $M$. rapax larvae, no predation was observed, regardless of the larval density in the tanks. This was confirmed according to the fish stomach contents.

An unprecedented larval behavior was observed in both crab species. In both light and dark tanks, larvae actively avoided the water immediately surrounding the fish. We observed an avoidance zone forming around the fish, with a radius between 3.0 and 5.0 $\mathrm{cm}$, approximately. As the fish swam, that gap also moved with them, with larvae actively maintaining a minimum distance from the predators.

\section{Swimming behavior}

The swimming behavior in newly hatched larvae of the six decapod crustaceans studied herein in response to isolated stimuli is summarized in Tab. 2 .

Table 2. Swimming behavior in newly hatched larvae of six decapod crustaceans (Macrobrachium olfersii, Macrobrachium acanthurus, Ucides cordatus, Minuca rapax, Callinectes danae and Emerita brasiliensis) in response to isolated stimuli. $(-)=$ negative response, (nt) $=$ not tested.

\begin{tabular}{|c|c|c|c|c|}
\hline \multirow{2}{*}{ Species } & \multicolumn{4}{|c|}{ Swimming behavior tests (newly hatched larvae) } \\
\hline & Geotaxis & Salinity gradient & Low-pressure zone & Planktivorous fish contact \\
\hline $\begin{array}{l}\text { Macrobrachium } \\
\text { acanthurus }\end{array}$ & $\begin{array}{c}(-) \\
78 \pm 1.9 \% \\
(75.5-80 \%) \\
\text { of the larvae remained above } 15 \mathrm{~cm} \text { depth }\end{array}$ & $\begin{array}{l}\text { concentration above halocline } \\
\qquad \begin{array}{l}63 \pm 1.7 \% \\
(61-65 \%)\end{array} \\
\text { of the larvae remained in salinities } 18 \text { to } 30\end{array}$ & escaping behavior & nt \\
\hline $\begin{array}{l}\text { Macrobrachium } \\
\text { olfersii }\end{array}$ & $\begin{array}{c}(-) \\
67 \pm 2.1 \% \\
(65-70 \%) \\
\text { of the larvae remained above } 15 \mathrm{~cm} \text { depth }\end{array}$ & $\begin{array}{l}\text { concentration in halocline } \\
\qquad \begin{array}{l}93 \pm 2.2 \% \\
(90-95 \%)\end{array} \\
\text { of the larvae remained in salinities } 16 \text { to } 20\end{array}$ & escaping behavior & nt \\
\hline $\begin{array}{l}\text { Emerita } \\
\text { brasiliensis }\end{array}$ & no significant response & $\begin{array}{l}\text { concentration in higher salinity } \\
\qquad 80 \pm 2.7 \% \\
(77-83.5 \%) \\
\text { of the larvae remained in salinity } 30\end{array}$ & no response & $\mathrm{nt}$ \\
\hline $\begin{array}{l}\text { Callinectes } \\
\text { danae }\end{array}$ & $\begin{array}{c}(-) \\
91 \pm 1.3 \% \\
(90-93 \%) \\
\text { of the larvae remained above } 15 \mathrm{~cm} \text { depth }\end{array}$ & $\begin{array}{l}\text { concentration in higher salinity } \\
\qquad \begin{array}{l}74 \pm 3.0 \% \\
(71-78 \%)\end{array} \\
\text { of the larvae remained in salinity } 30\end{array}$ & no response & avoid predator \\
\hline Ucides cordatus & $\begin{array}{c}(-) \\
75 \pm 2.9 \% \\
(71-78 \%) \\
\text { of the larvae remained above } 15 \mathrm{~cm} \text { depth }\end{array}$ & $\begin{array}{l}\text { concentration in higher salinity } \\
\qquad 85 \pm 5.0 \% \\
(80-92 \%) \\
\text { of the larvae remained in salinity } 30\end{array}$ & no response & $\mathrm{nt}$ \\
\hline Minuca rapax & no significant response & $\begin{array}{l}\text { concentration in higher salinity } \\
\qquad 84 \pm 1.4 \% \\
(82-85.5 \%) \\
\text { of the larvae remained in salinity } 30\end{array}$ & no response & avoid predator \\
\hline
\end{tabular}

\section{Discussion}

In the present study, spawning of the six decapod species always occurred at the beginning of the dark period. According to several studies, many decapod species synchronize the larval release with nocturnal tides, especially ebb tides, in nature (see Anger, 2001). In Macaé River estuary (SE-Brazil), Almeida et al. (2013) observed the higher larval densities of $U$. cordatus, Gelasiminae ("Uca spp.", fiddler-crabs), Sesarmidae, and Macrobrachium spp. 
during night ebb tides. On the Argentine coast, the same pattern was observed by Bas et al. (2009) for zoea I of Neohelice granulata (Dana, 1851), a very abundant crab in the South Atlantic. The spawning synchrony with the highest amplitude nocturnal ebb tides is related to the avoidance of visual predators and to maximize larval dispersal (Morgan and Christy, 1995). The initial effort to improve dispersal could also avoid cannibalism, particularly when adults are plankton feeders. That is the case for the mole crab E. brasiliensis. In our preliminary tests we observed that females captured newly hatched larvae and, for that, adjustments on the tanks were necessary.

In the absence of a proper experiment, we observed positive phototaxis in the larvae of all studied species. Several species of decapods show positive phototaxis during the early larval stages, as shown in the revision by Epifanio and Cohen (2016). However, according to the same authors, an inadequate experimental methodology could mask real larval behavior. Authors, such as Tankersley et al. (1995), and Webley and Connolly (2007), among others, recommend methods that simulate the angular light distribution and make the experimental tank conditions more similar to those observed in natural environments. In a study with different light intensities and close to natural angulation, Forward and Buswell (1989) did not detect phototaxis responses in zoea I by fiddler crabs Leptuca pugilator (Bosc, 1802) and Minuca pugnax (Smith, 1870). The same authors also investigated phototaxis in Callinectes sapidus Rathbun, 1896 (close related to $C$. danae), in which zoea I demonstrated a weak negative phototaxis, especially when submitted to higher light intensities.

Gravity, along with pressure and luminosity, is an important environmental factor capable of influencing and determining the behavioral responses in decapod larvae. Negative geotaxis was observed in the larvae of M. olfersii, M. acanthurus, C. danae, and U. cordatus in the present study. Other species like Rhithropanopeus harrisi (Gould, 1841) (at $25^{\circ} \mathrm{C}$ ) and Menippe mercenaria (Say, 1818) are also known to show negative geotaxis in zoea I (Ott and Forward, 1976; Gravinese, 2018). The vertical positioning in the water column can be a determinant in horizontal larval transport, facilitating their dispersion or retention near to the habitat of the adults (Queiroga and Blanton, 2005). Usually, negative geotaxis during ebb tides - with larvae positioned in subsurface waters - increases larval transport.

Considering the lack of tidal currents in the experimental tanks, careful statements about the relationship between negative geotaxis and larval export or retention strategies are necessary. The field study of Almeida et al. (2013) found larvae of Macrobrachium spp. and U. cordatus associated with surface waters during ebb tides, especially at night, indicating an export strategy. In Callinectes, Sulkin (1984) and McConaugha (1988) also observed larval export strategies, including negative geotaxis in zoea I. Thus, the results observed in the present study approximate the observations of larval export strategy for these species in nature.

The rapid larval transport after spawning can be a determining factor for some species. In M. olfersii, the negative geotaxis and the association with surface water are very relevant for larval survival. Almeida et al. (2017) studied an M. olfersii population in southeastern Brazil where spawning occurred upstream, some kilometers away from the estuary. The larvae of this population are transported down the river for a few hours or days until they reach brackish or saltwater. During this transport, the larvae suffer from starvation and osmotic stress. These authors observed that $M$. olfersii larvae were more resistant to starvation when compared to $M$. acanthurus in the same river, the latter being released much closer to the estuary. The association of newly hatched $M$. olfersii larvae with the subsurface water can guarantee faster transport to the estuarine region, ensuring an increase in survival rates.

In our study, newly hatched larvae of E. brasiliensis and $M$. rapax did not respond to gravity, remaining scattered throughout the water column. Unfortunately, there are few records of the larval dynamics in $E$. brasiliensis. In a study with Emerita analoga (Stimpson, 1857), a closely related species on the coast of Chile, Mujica et al. (2014) observed higher density of zoea I close to the adult populations in the coastal region. These authors indicated that only intermediate larval stages were found at more distant sampling spots. Sorte et al. (2001), in a study on the influence of El Niño on E. analoga larval transport, have suggested that in some populations a broader dispersal may result in losing the best conditions for settlement and 
recruitment. They speculated that mole crabs present larval behavior that partially restrains dispersal. Data are still insufficient to categorically state whether mole crab species have a larval retention strategy.

In fiddler crab larvae, some evidence points to endogenous rhythms being more determinant oflarval vertical distribution, than exogenous environmental factors (Epifanio and Cohen, 2016). López-Duarte et al. (2011) observed that fiddler crabs with different distribution sites (coastal or riverine, mostly) show different larval behavior. In their study, the vertical swimming behavior in zoea I of $M$. rapax was considered arrhythmic or not rhythmic. This pattern is similar to the absence of a geotaxis response observed in our study. López-Duarte et al. (2011) state that the arrhythmic vertical positioning has been frequently observed in fiddler crabs that live closer to the sea, in which a single tidal cycle is sufficient to take the larvae to saline waters. It is noteworthy that $M$. rapax females of our study were obtained in a location with these conditions, in a coastal lagoon with a predominance of saline waters.

The results of vertical salinity gradient tests were as expected. All species in this study, as observed in many other decapod larvae, showed a preference for higher salinities. Compared to adults, larval forms are more sensitive to osmotic changes and low salinities. Their reduced size, high surface area to volume ratio, and less than effective cuticle, contribute to interrupted development in fresh or less saline waters. Here, the stimulus caused by the vertical salinity variation exceeded the geotaxis response. Larvae that showed negative geotaxis, swimming in subsurface waters in the uniformly salinity column (= $30 \mathrm{PSU}$ ), modified their behavior in the presence of a halocline. This behavior was mainly observed in C. danae and U. cordatus and indicates larval actively sinking when surface waters present low salinity levels. According to Diele and Simith (2006), U. cordatus larvae need salinities above 15 PSU to complete larval development, with better results observed at a salinity of 30 PSU. Despite the lack of studies on C. danae larval development under different salinities, it is known that ovigerous females migrate to waters with higher salinities to spawn (Branco and Masunari, 2000; Keunecke et al., 2012). This behavior is a strategy to maximize the dispersal and survival of newly hatched larvae.

Previous studies have also pointed out the need for saltwater for successful larval development in the other species analyzed. Simith et al. (2014) indicated that $M$. rapax presents successful larval development in salinities between 25 and 35 PSU. According to Choudhury (1971), M. acanthurus larvae showed better development in salinities between 15 and 25 PSU. However, larvae of M. olfersii, a species in which adult populations occupy freshwater environments, can grow in any salinities above 7 PSU (McNamara et al., 1986). This difference can potentially explain why, in the halocline experiments, $M$. olfersii larvae were concentrated in less saline waters (16-20 PSU), when compared to $M$. acanthurus (18-30). Studies on the effects of salinity on E. brasiliensis larval development are lacking. However, a study on the effects of freshwater effluents (e.g., sewage or rainwater) on beaches where sand crabs occur (including juveniles), indicated a preference for areas washed by more saline waters (Lercari and Defeo, 1999). The sand crab larvae probably have a preference for saltwater, as well as juveniles and adults.

In the present study, we observed Macrobrachium larvae quickly moving away when they detected lowpressure zones. We believe this behavior is a response to predators that suck their prey, especially fishes. Most fish species feed on plankton during part, or all, of their life cycles, and they are noted as important predators of crustacean larvae (Hovel and Morgan, 1997). Planktivorous fish may attack their planktonic prey individually or engulf a volume of water and retain the plankton and particles (Lazzaro, 1987). The first feeding strategy involves a rapid expansion of the buccal cavity, which results in a pressure drop inside the oral cavity and creates water flow towards the predator's mouth (Higham et al., 2006). In the second feeding strategy, fish keep the mouth open wide while swimming quickly, or use rhythmic suctioning to capture their prey while swimming slowly or remaining stationary. Strategies that involve suction are very common and Macrobrachium larvae escape responses, herein observed, are probably an instinctive behavior to avoid predators. In response to predators, adult prawns and shrimps (including 
Macrobrachium species) also produce strong swimming pulses using the tail fan (tail-flip escape response) (Arnott et al., 1998). This very common behavior develops quite early. In his work, Morgan (1987) claims that shrimp larvae (Palaemon pugio (Holthuis, 1949) - Palaemonidae) perform strong escape swimming pulses and show a higher ability to escape from a predatory fish when compared to crab larvae. However, these authors registered larval escaping reactions only after contact with the predator. Although P. pugio and Macrobrachium larvae are morphologically similar, they may present behavioral differences due to variations between the studied environments or due to the experimental model. The absence of larval responses to low pressure in the other species of the present study show that either: (1) they lack a behavioral response to low-pressure zones; or (2) there is experimental inadequacy, considering their most common predators and the regions where the larvae develop. It is also possible that just the presence of low-pressure zones does not produce behavioral escape reactions in these species, having further requirements for chemical, visual or tactile stimuli.

Finally, we demonstrate, for the first time, that zoea larvae (of $M$. rapax and C. danae) actively maintain a minimum distance from a planktivorous fish. Epifanio and Cohen (2016), in their review, stated that the locomotive behavior of crab larvae, usually regulated by external signals detected in the water column, determines the vertical distribution and predatorprey interactions. In our work, the avoidance reaction to the predator occurred in both the light and dark. In addition to the visual or tactile stimuli - direct contact with the predator or with the water movement created by them - crab zoea also present a chemical detection capacity. Charpentier and Cohen (2015) affirmed that light is an important stimulus in the behavior of zoea, and pointed out that chemical cues and kairomones can increase swimming responses. Kairomones are products of amino acid degradation in the mucus of the fish body, and their concentration can affect the swimming behavior of crab larvae (Cohen and Forward Jr., 2003). When considering all the previous laboratory studies on crab larval predation, we ask the question why such avoidance behavior has not been recorded before? The answer probably lies in the high larval density used in our tests (800 to 2200 larvae $\mathrm{l}^{-1}=800,000$ to $2,200,000$ larvae $\left.\mathrm{m}^{-3}\right)$. These high densities may have increased the probability of detection of this larval behavior, simply because the gap around the fish was more easily seen. We believe that this defense/avoidance behavior of the larvae should be further investigated as it is likely to have high importance in the first hours of larval life.

\section{ACKNOWLEDGMENTS}

We are grateful for the logistical support from Laboratório Integrado de Zooplâncton e Ictioplâncton (LIZI-UFRJ) of Universidade Federal do Rio de Janeiro, and from the research laboratory of Faculdades Integradas Maria Thereza (Famath), Niterói - Brazil. We also thank the reviewers for their valuable contributions, and to $\mathrm{PhD}$. Pedro Castanheira for the English review. This research did not receive any specific grant from funding agencies in the public, commercial, or not-for-profit sectors.

\section{References}

Almeida, E.V.; Bonecker, S.L.C. and Fernandes, L.D.A. 2013. Exportação e Retenção de Decápodes Planctônicos (Crustacea) no Estuário do Rio Macaé (RJ) (22²2 S-041\%46 W). Atlântica (Rio Grande), 35: 23-34.

Almeida, E.V.; Guimarães, R.V.; Caldeira, M.S.P.R.; Azevedo, L.C. and Bonecker, S. L.C. 2017. Efeito de inanição nos primeiros estádios larvais dos camarões de água doce Macrobrachium acanthurus e Macrobrachium olfersii (Crustacea: Decapoda: Palaemonidae), em laboratório. Semioses, 11: 48-57.

Amundsen, P.A.; Gabler, H.M. and Staldvik, F.J. 1996. A new approach to graphical analysis of feeding strategy from stomach contents data - modification of the Costello method. Journal of Fish Biology, 48: 607-614.

Anger, K. 2001. The Biology of Decapod Crustacean Larvae. Crustaceans Issues, 14. Lisse/ Abingdon/ Exton (PA)/ Tokyo, A.A. Balkema Publishers, 419p.

Arnott, S.; Neil, D. and Ansell, A. 1998. Tail-flip mechanism and size-dependent kinematics of escape swimming in the brown shrimp Crangon crangon. Journal of Experimental Biology, 201: 1771-1784.

Bas, C.; Luppi, T.; Spivak, E. and Schejter, L. 2009. Larval dispersion of the estuarine crab Neohelice granulata in coastal marine waters of the Southwest Atlantic. Estuarine, Coastal and Shelf Science, 83: 569-576.

Bosc, L.A.G. 1802. Histoire naturelle des Crustacés, contenant leur description et leurs moeurs, avec figures dessiées d'après nature, vol. 1. Paris, Deterville, 258p.

Branco, J.O. and Masunari, S. 2000. Reproductive ecology of the blue crab, Callinectes danae Smith, 1869 in the Conceição 
Lagoon system, Santa Catarina Isle, Brazil. Revista Brasileira de Biologia, 60: 17-27.

Charpentier, C.L. and Cohen, J.H. 2015. Chemical cues from fish heighten visual sensitivity in larval crabs through changes in photoreceptor structure and function. Journal of Experimental Biology, 218: 3381-3390.

Choudhury, P.C. 1971. Laboratory rearing of larvae of the palaemonid shrimp Macrobrachium acanthurus (Wiegmann, 1836). Crustaceana, 21: 113-126.

Cohen, J.H. and Forward, R.B. Jr. 2003. Ctenophore kairomones and modified amino sugar disaccharides alter the shadow response in a larval crab. Journal of Plankton Research, 25: 203-213.

Dana, J.D. 1851. On the Classification of the Cancroidea. American Journal of Science and Arts, Second series, 12: 283-291.

Diele, K. and Simith, D.J.B. 2006. Salinity tolerance of northern Brazilian mangrove crab larvae, Ucides cordatus (Ocypodidae): Necessity for larval export? Estuarine, Coastal and Shelf Science, 68: 600-608.

Epifanio, C.E. and Cohen J.H. 2016. Behavioral adaptations in larvae of brachyuran crabs: a review. Journal of Experimental Marine Biology and Ecology, 482: 85-105.

Forward, R.B. Jr. and Buswell, C.U. 1989. A comparative study of behavioural responses of larval decapod crustaceans to light and pressure. Marine Behaviour and Physiology, 16: 43-56.

Forward, R.B. Jr.; Tankersley, R.A. and Welch, J.M. 2003. Selective tidal stream transport of the blue crab Callinectes sapidus: an overview. Bulletin of Marine Science, 72: 347-365.

Gould, A.A. 1841. Report on the Invertebrata of Massachusetts: comprising the Mollusca, Crustacea, Annelida, and Radiata. Folson, Wells \& Thurston, 373p.

Gravinese, P.M. 2018. Vertical swimming behavior in larvae of the Florida stone crab, Menippe mercenaria. Journal of Plankton Research, 40: 643-654.

Higham, T.E.; Day, S.W. and Wainwright, P.C. 2006. The pressures of suction feeding: the relation between buccal pressure and induced fluid speed in centrarchid fishes. Journal of Experimental Biology, 209: 3281-3287.

Holthuis, L.B. 1949. Note on the species of Palaemonetes (Crustacea Decapoda) found in the United States of America. Proceedings van de Koninklijke Nederlandsche Akademie van Wetenschappen, 52: 87-95.

Hovel, K.A. and Morgan, S.G. 1997. Planktivory as a selective force for reproductive synchrony and larval migration. Marine Ecology Progress Series, 157: 79-95.

Jamovi. 2020. The jamovi project. (Version 1.2) [Computer Software]. Available at https://jamovi.org. Accessed on 10 October 2020.

Keunecke, K.A.; D’Incao, F.; Verani, J.R. and Vianna, M. 2012. Reproductive strategies of two sympatric swimming crabs Callinectes danae and Callinectes ornatus (Crustacea: Portunidae) in an estuarine system, south-eastern Brazil. Journal of the Marine Biological Association of the UK, 92: 343-347.

Koettker, A.G. and Freire, A.S. 2006. Spatial and temporal distribution of decapod larvae in the subtropical waters of the Arvoredo archipelago, SC, Brazil. Iheringia - Série Zoologia, 96: $31-40$.
Kunze, H.B.; Morgan, S.G. and Lwiza, K.M. 2013. Field test of the behavioral regulation of larval transport. Marine Ecology Progress Series, 487: 71-87.

Lazzaro, X. 1987. A review of planktivorous fishes: their evolution, feeding behaviours, selectivities, and impacts. Hydrobiologia, 146: 97-167.

Lercari, D. and Defeo, O. 1999. Effects of freshwater discharge in sandy beach populations: the mole crab Emerita brasiliensis in Uruguay. Estuarine, Coastal and Shelf Science, 49: 457-468.

Linnaeus, C. von. 1763. Cancer cordatus. Amoenitates Academice, 6: 414 .

López-Duarte, P.C.; Christy, J.H. and Tankersley, R.A. 2011. A behavioral mechanism for dispersal in fiddler crab larvae (genus $U_{c a}$ ) varies with adult habitat, not phylogeny. Limnology and Oceanography, 56: 1879-1892.

McConaugha, J.R. 1988. Export and reinvasion of larvae as regulators of estuarine decapod populations. American Fisheries Society Symposium, 3: 90-103.

McNamara, J.C.; Moreira, G.S. and Souza, S.C. 1986. The effect of salinity on respiratory metabolism in selected ontogenetic stages of the freshwater shrimp Macrobrachium olfersii (Decapoda, Palaemonidae). Comparative Biochemistry and Physiology, 83: 359-364.

Morgan, S.G. 1987. Adaptive significance of hatching rhythms and dispersal patterns of estuarine crab larvae: avoidance of physiological stress by larval export? Journal of Experimental Marine Biology and Ecology, 113: 71-78.

Morgan, S.G. and Christy, J.H. 1995. Adaptive significance of the timing of larval release by crabs. American Naturalist, 145: 457-479.

Morgan, S.G. and Christy, J.H. 1997. Planktivorous fishes as selective agents for reproductive synchrony. Journal of Experimental Marine Biology and Ecology, 209: 89-101.

Mujica, A.; Nava, M.L. and Vargas, A. 2014. Dispersion of Emerita analoga (Stimpson, 1857) larvae in northern coast of Chile $\left(25^{\circ}-31.5^{\circ} \mathrm{S}\right)$. Latin American Journal of Aquatic Research, 42(3): 418-426.

Otegui, A.C.P. and Soares-Gomes, A. 2007. Desenvolvimento 'in vitro' de larvas e juvenis de Emerita brasiliensis Schmitt (Crustacea, Decapoda, Hippidae) sob diferentes condições de temperatura, salinidade e regime alimentar. Revista Brasileira de Zoologia, 24: 277-282.

Ott, F.S. and Forward, R.B. Jr. 1976. The effect of temperature on phototaxis and geotaxis by larvae of the crab Rhithropanopeus harrisii (Gould). Journal of Experimental Marine Biology and Ecology, 23: 97-107.

Queiroga, H. and Blanton, J. 2005. Interactions between behaviour and physical forcing in the control of horizontal transport of decapod crustacean larvae. Advances in Marine Biology, 47: 107-214.

Quoy, J.R.C. and Gaimard, J.P. 1825. Description des Poissons. Chapter IX. In: Freycinet, L. Voyage autour du monde, entrepris par ordre du roi. Exécuté sur les corvettes de S.M. L'Uranie et La Physicienne, pendant les années 1817, 1818, 1819 et 1820 . Paris, Pillet Aîne, p. 329-616, pls. 43-65.

Rathbun, M.J. 1896. The genus Callinectes. Proceedings of the United States National Museum, 18(1070): 349-375, pls. XIII-XXVIII. 
Saiz, E. 2009. Swimming dynamics of zooplankton. In: Duarte, C.M. and Lot, A. (eds), Marine Ecology. Encyclopedia of Life Support System. Paris, UNESCO, EOLSS Publishers, 25p.

Say, T. 1818. Appendix to the account of the Crustacea of the United States. Journal of the Academy of Natural Sciences, Philadelphia, 1: 445-458.

Schmitt, W.L. 1935. Crustacea Macrura and Anomura of Porto Rico and the Virgin Islands. p. 125-227. In: Scientific Survey of Porto Rico and the Virgin Islands, vol. 15 - part 2. New York, New York Academy of Sciences.

Seuront, L.; Yamazaki, H. and Souissi, S. 2004. Hydrodynamic disturbance and zooplankton swimming behavior. Zoological Studies, 43: 376-387.

Simith, D.J.B.; Pires, M.A.B.; Abrunhosa, F.A.; Maciel, C.R. and Diele, K. 2014. Is larval dispersal a necessity for decapod crabs from the Amazon mangroves? Response of Uca rapax zoeae to different salinities and comparison with sympatric species. Journal of Experimental Marine Biology and Ecology, 457: 22-30.

Smith, S.I. 1869. Notice of the Crustacea collected by Prof. C.F. Hartt on the coast of Brazil in 1867. Transactions of the Connecticut Academy of Arts and Sciences, 2: 1-41.

Smith, S.I. 1870. Notes on American Crustacea. Number I. Ocypodoidea. Transactions of the Connecticut Academy of Arts and Sciences, 2: 113-176, pls. 2-5.
Sorte, C.J.; Peterson, W.T.; Morgan, C.A. and Emmett, R.L. 2001. Larval dynamics of the sand crab, Emerita analoga, off the central Oregon coast during a strong El Niño period. Journal of Plankton Research, 23: 939-944.

Stimpson, W. 1857. Notices of new species of Crustacea of western North America; being an abstract from a paper to be published in the journal of the Society. Proceedings of the Boston Society of Natural History, 6: 84-89.

Sulkin, S.D. 1984. Behavioral basis of depth regulation in the larvae of brachyuran crabs. Marine Ecology Progress Series, 15: 181-205.

Tankersley, R.A; McKelvey, L.M. and Forward, R.B. Jr. 1995. Responses of estuarine crab megalopae to pressure, salinity and light: implications for flood-tide transport. Marine Biology, 122: 391- 400.

Veloso, V.G.; Silva, E.S.; Caetano, C.H.S. and Cardoso, R.S. 2006. Comparison between the macroinfauna of urbanized and protected beaches in Rio de Janeiro State, Brazil. Biological Conservation, 127: 510-515.

Webley, J.A.C. and Connolly, R.M. 2007. Vertical movement of mud crab megalopae (Scylla serrata) in response to light: Doing it differently down under. Journal of Experimental Marine Biology and Ecology, 341: 196-203.

Wiegmann, A. 1836. Beschreibung einiger neuen Crustaceen des Berliner Museums aus Mexiko und Brasilien. Archiv für Naturgeschichte, 2: 145-152. 